\title{
Leuprolide Acetate 1-Month Depot for Central Precocious Puberty: Hormonal Suppression and Recovery
}

\author{
E. Kirk Neely, ${ }^{1}$ Peter A. Lee, ${ }^{2}$ Clifford A. Bloch, ${ }^{3}$ Lois Larsen, ${ }^{4}$ Di Yang, ${ }^{4}$ \\ Cynthia Mattia-Goldberg, ${ }^{4}$ and Kristof Chwalisz ${ }^{4}$ \\ ${ }^{1}$ Division of Pediatric Endocrinology and Diabetes, Stanford University Medical Center, Room G313, Stanford, CA 94305-5208, USA \\ ${ }^{2}$ The Milton S. Hershey Medical Center, College of Medicine, Pennsylvania State University, Hershey, PA 17033, USA \\ ${ }^{3}$ Pediatric Endocrine Associates, 8200 E. Belleview, Suite 510-E, Greenwood Village, CO 80111, USA \\ ${ }^{4}$ Abbott Laboratories, 200 Abbott Park Road, Abbott Park, North Chicago, IL 60064, USA
}

Correspondence should be addressed to E. Kirk Neely, neely@stanford.edu and Peter A. Lee, leepa@iupui.edu

Received 18 October 2010; Accepted 7 December 2010

Academic Editor: Christopher J. H. Kelnar

Copyright ( $) 2010$ E. Kirk Neely et al. This is an open access article distributed under the Creative Commons Attribution License, which permits unrestricted use, distribution, and reproduction in any medium, provided the original work is properly cited.

\begin{abstract}
Methods. This prospective US multicenter trial of leuprolide acetate 1-month depot (7.5-15 mg) for central precocious puberty utilized an open-label treatment period, long-term follow-up, and adult callback. Forty-nine females $<9$ years old with Tanner breast stage $\geq 2$ before 8 years and 6 males $<10$ years old with Tanner genital stage $\geq 2$ before 9 years with stimulated LH $\geq 10$ IU/L and bone age advance $\geq 1$ year were enrolled. Results. Subjects were treated for $3.9 \pm 2.0$ years. Mean peak GnRH-stimulated LH and FSH were prepubertal after the first dose and remained suppressed throughout treatment. During treatment, mean estradiol decreased to the limit of detection and mean testosterone decreased but remained above prepubertal norms. During posttreatment follow-up $(3.5 \pm 2.2$ years $)$, all patients achieved a pubertal hormonal response within 1 year and menses were reported in all females $\geq 12$ years old. No impairment of reproductive function was observed at adulthood (mean age: 24.8 years).
\end{abstract}

\section{Introduction}

Children with central precocious puberty (CPP) prematurely develop pubertal pulsatile release of gonadotropin-releasing hormone $(\mathrm{GnRH})$, leading to an increase in gonadotropin and sex steroid levels, development of secondary sexual characteristics, advancement of bone age (BA), and consequent reduction in adult height $(\mathrm{AH})$ [1]. Treatment goals include hormonal suppression, cessation of development of secondary sex characteristics, halting or preventing menarche, and preservation of $\mathrm{AH}$. If left untreated, children with CPP can also face psychological challenges resulting from premature physical maturation that contrasts with their immature emotional development [2].

GnRH analogs (GnRHa) have been the standard of care for CPP for over 15 years [1]. Continuous exposure to GnRHa desensitizes pituitary gonadotroph receptors and suppresses luteinizing hormone (LH) and follicle stimulating hormone (FSH) secretion. Efficacy of various GnRHa in CPP has been established [3-14], but truly long-term studies are limited, particularly for leuprolide. Furthermore, most
GnRHa studies have not utilized sensitive gonadotropin assays that can accurately assess the extent of hormonal suppression. The objectives of this open-label treatment study of leuprolide acetate 1-month depot and long-term observational extension study were to evaluate the suppression of the pituitary-gonadal axis and the clinical sexual characteristics during treatment and to examine the longterm impact on the growth pattern, $\mathrm{AH}$, and reproductive function of children treated for CPP. Initial results from the treatment period led to FDA approval of leuprolide acetate 1-month depot for the treatment of CPP. Here we report hormonal suppression during the treatment period, safety, recovery of hormone secretion, and long-term reproductive outcomes. A separate paper reports the auxological outcomes [15].

\section{Patients and Methods}

2.1. Patients. All patients were naïve to GnRHa therapy. Females with Tanner breast stage $\geq 2$ before 8.0 years old and chronological age (CA) $<9.0$ years at initiation of therapy 
and males with Tanner genital stage $\geq 2$ before 9.0 years and $\mathrm{CA}<10.0$ years were eligible. Inclusion criteria included GnRH-stimulated peak $\mathrm{LH} \geq 10 \mathrm{IU} / \mathrm{L}, \mathrm{BA}$ advance $\geq 1$ year beyond CA by Fels Method [16], no prior treatment with GnRHa, no history of central nervous system irradiation, and anticipated treatment for $\geq 1$ year. Patients had an MRI of the brain, hypothalamus, and pituitary prior to the initiation of therapy. Institutional review board approval was obtained at each site, and written informed consent was provided by the subject and the subject's parent or legal guardian prior to any study-related procedures.

2.2. Methods. This study at 9 US centers consisted of an open-label treatment period with leuprolide acetate 1-month depot and a long-term follow-up period. Clinical sexual characteristics, LH, FSH, and sex steroids during and after treatment were assessed. After a screening visit, treatment period study visits occurred at week $0,4,8,12,24,36$, and 48, and then every 24 weeks. Study visits included a physical examination with Tanner staging, weight, and triplicate heights by stadiometer. Laboratory assessments included GnRH stimulation testing to determine basal and peak stimulated LH and FSH using Factrel $100 \mu \mathrm{g}$ IV with blood samples at 0, 20, 40, 60, and 90 minutes. LH and FSH were measured by dissociation-enhanced lanthanide fluorescence immunoassay (DELFIA), with a sensitivity of $0.15 \mathrm{IU} / \mathrm{L}$ for $\mathrm{LH}$ and $0.5 \mathrm{IU} / \mathrm{L}$ for $\mathrm{FSH}$ (University of Pittsburgh Children's Hospital; Pittsburgh, PA). Estradiol (or testosterone) levels were obtained at 0 and 90 minutes and were measured by radioimmunoassay (University of Pittsburgh Children's Hospital, Pittsburgh, PA) with a lower limit of $18.36 \mathrm{pmol} / \mathrm{L}(5 \mathrm{pg} / \mathrm{mL})$ for estradiol and $0.347 \mathrm{nmol} / \mathrm{L}(10 \mathrm{ng} / \mathrm{dL})$ for testosterone. Hematology and chemistry analyses were performed by Covance (formerly Scicor, Indianapolis, IN). Adverse events were assessed at each study visit. Treatment-emergent adverse events were coded using the Coding Symbols for Thesaurus of Adverse Reaction Terms (COSTART) dictionary.

Leuprolide acetate 1-month depot was started at a dose of at least $300 \mu \mathrm{g} / \mathrm{kg}(7.5,11.25$, or $15.0 \mathrm{mg})$ administered intramuscularly (IM) every 28 days. Incremental dose adjustments of $3.75 \mathrm{mg}$ were made at each clinic visit for specific criteria or for weight increase. Doses were increased at the week 8 study visit if the peak $\mathrm{LH}$ value from the week $4 \mathrm{GnRH}$ stimulation test exceeded $1.75 \mathrm{IU} / \mathrm{L}$. At week 12 and beyond, doses were to be increased for peak LH value $>1.75 \mathrm{IU} / \mathrm{L}$, testosterone $>0.347 \mathrm{nmol} / \mathrm{L}(10 \mathrm{ng} / \mathrm{dL})$, estradiol $>18.36 \mathrm{pmol} / \mathrm{L}(5 \mathrm{pg} / \mathrm{mL})$, or menstrual bleeding or spotting. Therapy was discontinued at an age appropriate for reinitiation of puberty at the discretion of the investigator.

After discontinuation of treatment, patients could enter a long-term observational follow-up study with visits occurring every 6 months ( 1 month equal to 28 days) until laboratory measurements reached pubertal levels, then annually until the age of 21 years. Follow-up study visits included Tanner staging, height and weight, and a questionnaire on menstrual history. Basal and stimulated gonadotropins and estradiol/testosterone were measured at each visit until a pubertal response was observed; thereafter only basal levels were measured. Pubertal response was defined by all of the following: females, peak $\mathrm{LH}>6 \mathrm{IU} / \mathrm{L}$, peak FSH $\geq 5$ IU/L, estradiol $\geq 55.1 \mathrm{pmol} / \mathrm{L}(15 \mathrm{pg} / \mathrm{mL})$; males, peak LH $>10 \mathrm{IU} / \mathrm{L}$, peak FSH $\geq 2.5 \mathrm{IU} / \mathrm{L}$, testosterone $\geq 2.60 \mathrm{nmol} / \mathrm{L}$ $(75 \mathrm{ng} / \mathrm{dL})$. Menses was defined as $\geq 3$ consecutive days of uterine bleeding. A final visit at adulthood was conducted to assess adult height and reproductive function by questionnaire and pelvic ultrasound.

2.3. Statistics. Clinical suppression was defined as an improvement or no change in Tanner staging. The development of clinical sexual characteristics posttreatment was defined as an increase in Tanner stage from the end of treatment. Patients who entered the study at Tanner stage 5 were not included in these analyses. Summary statistics were calculated for age, menses, adverse events, and gonadotropin and sex steroid levels. For levels below the detection thresholds, calculations substituted the relevant threshold value. Standard deviations or ranges (parentheses) are reported in text. Significance tests for change versus no change were performed using paired $t$-tests.

\section{Results}

Subjects were treated for an average of $3.9 \pm 2.0$ years and followed for an average posttreatment period of $3.5 \pm 2.2$ years.

3.1. Baseline Characteristics. Fifty-five patients, naïve to GnRHa treatment, met the inclusion criteria of peak LH $\geq 10 \mathrm{IU} / \mathrm{L}$ and $\mathrm{BA}$ advance $\geq 1$ year and entered the study. Subject demographics and baseline characteristics for the female $(n=49)$ and male $(n=6)$ patients are summarized in Table 1 . Twenty patients (18/49 females and 2/6 males) had a history of neurological disorder, including head trauma $(n=4)$, seizure disorder $(n=2)$, suprasellar cyst $(n=2)$, meningitis $(n=2)$, hypothalamic tumor, hamartoma, spina bifida, hydrocephalus, developmental delay, and hypotonia (all $n=1)$. The remaining patients $(35 / 55)$ were diagnosed with idiopathic CPP.

Mean peak GnRH-stimulated $\mathrm{LH}$ was $35.1 \pm 21.32 \mathrm{IU} / \mathrm{L}$ at baseline. The peak LH occurred at the 20- or 40minute blood draw in 51/55 subjects, and in all patients the diagnostic threshold of $10 \mathrm{IU} / \mathrm{L}$ was surpassed at both timepoints. Mean basal LH was $1.98 \mathrm{IU} / \mathrm{L}$ (range: <0.15$11.1) ; 6 / 55$ pretreatment basal LH levels were $<0.5$ IU/L. Peak $\mathrm{LH}$ and basal LH were moderately correlated $(r=0.322)$, but peak LH was more strongly correlated with peak FSH $(r=0.652)$. Serum estradiol levels at 0 and 90 minutes were undetectable $(<18.36 \mathrm{pmol} / \mathrm{L}(5 \mathrm{pg} / \mathrm{mL}))$ in $16 / 49$ and 21/49 females, respectively. The 0 - and 90-minute mean estradiol concentrations were $56.9 \mathrm{pmol} / \mathrm{L}(15.5 \mathrm{pg} / \mathrm{mL})$ and $56.2 \mathrm{pmol} / \mathrm{L}(15.3 \mathrm{pg} / \mathrm{mL})$, respectively. In males, 0 - and 90 minute mean testosterone concentrations were $6.9 \mathrm{nmol} / \mathrm{L}$ $(199.8 \mathrm{ng} / \mathrm{dL})$ and $12.1 \mathrm{nmol} / \mathrm{L}(347.7 \mathrm{ng} / \mathrm{dL})$, respectively $(P=.023)$.

3.2. Treatment Period: Females. Mean age entering the study was $7.3 \pm 1.9$ years, mean age at discontinuation of treatment 
TABLE 1: Subject demographics and baseline characteristics.

\begin{tabular}{|c|c|c|c|}
\hline \multicolumn{2}{|l|}{ Characteristic } & $\begin{array}{l}\text { Female subjects } \\
\qquad N=49\end{array}$ & $\begin{array}{c}\text { Male subjects } \\
\qquad N=6\end{array}$ \\
\hline \multicolumn{4}{|l|}{ Race, $n$} \\
\hline \multicolumn{2}{|l|}{ Caucasian } & 30 & 4 \\
\hline \multicolumn{2}{|l|}{ African American } & 11 & 0 \\
\hline \multicolumn{2}{|l|}{ Asian } & 0 & 1 \\
\hline \multicolumn{2}{|l|}{ Hispanic } & 8 & 1 \\
\hline \multicolumn{4}{|l|}{ Age, years } \\
\hline \multicolumn{2}{|l|}{ Mean (SD) } & $7.3(1.9)$ & $7.9(2.0)$ \\
\hline \multicolumn{2}{|l|}{ Range } & $1.2-9.4^{\mathrm{a}}$ & $4.1-9.5$ \\
\hline \multicolumn{4}{|l|}{ Weight, kg } \\
\hline \multicolumn{2}{|l|}{ Mean (SD) } & $33.6(9.72)$ & $32.4(8.96)$ \\
\hline \multicolumn{2}{|l|}{ Range } & $13.0-52.2$ & $19.9-41.8$ \\
\hline \multicolumn{4}{|l|}{ Height, $\mathrm{cm}$} \\
\hline \multicolumn{2}{|l|}{ Mean (SD) } & $131.6(15.0)$ & $134.4(18.1)$ \\
\hline \multicolumn{2}{|l|}{ Range } & $84.6-154.7$ & $106.7-156.8$ \\
\hline \multicolumn{4}{|c|}{ Height standardized score } \\
\hline \multicolumn{2}{|l|}{ Mean (SD) } & $1.5(1.29)$ & $1.4(1.75)$ \\
\hline \multicolumn{2}{|l|}{ Range } & $-1.4-3.4$ & $-0.4-4.3$ \\
\hline \multicolumn{4}{|l|}{ Tanner stage, $n$} \\
\hline \multirow[t]{5}{*}{ Breast/genitalia } & $\mathrm{I}$ & $1^{\mathrm{b}}$ & 0 \\
\hline & II & 9 & 2 \\
\hline & III & 25 & 3 \\
\hline & IV & 13 & 1 \\
\hline & $\mathrm{V}$ & 1 & 0 \\
\hline \multicolumn{4}{|l|}{ Basal LH, IU/L } \\
\hline \multicolumn{2}{|l|}{ Mean (SD) } & $2.0(2.06)$ & $1.6(0.77)$ \\
\hline \multicolumn{2}{|l|}{ Range } & $<0.15-11.1$ & $0.73-2.6$ \\
\hline \multicolumn{4}{|l|}{ Peak LH, IU/L } \\
\hline \multicolumn{2}{|l|}{ Mean (SD) } & $36.7(21.8)$ & $21.2(9.1)$ \\
\hline \multicolumn{2}{|l|}{ Range } & $12.0-119.2$ & $13.5-38.8$ \\
\hline \multicolumn{4}{|c|}{ History of menstrual bleeding, $n$} \\
\hline \multicolumn{2}{|l|}{ No } & 36 & - \\
\hline \multicolumn{2}{|l|}{ Yes } & 12 & - \\
\hline
\end{tabular}

was $11.1 \pm 1.1$ years (7.3-13.3), and mean treatment duration was 3.8 years (0.23-9.8). Mean peak GnRH-stimulated $\mathrm{LH}$ and $\mathrm{FSH}$ in females declined into the prepubertal range after the first dose and remained suppressed throughout treatment (Figure 1). Mean peak LH decreased to $0.75 \mathrm{IU} / \mathrm{L}$ $(<0.15-3.9)$ by week 4 and numerically decreased after week 12 (Figure 1(a)). During treatment, 8/49 females had a peak stimulated $\mathrm{LH}$ value $\geq 1.75 \mathrm{IU} / \mathrm{L}$. Mean peak FSH decreased from 14.0 IU/L at baseline to $0.9 \mathrm{IU} / \mathrm{L}(<0.5-$ 3.19 ) by week 4 then numerically increased but remained $<1.7$ IU/L (Figure 1(b)).

Mean basal LH in females decreased from 2.0 IU/L at baseline to $0.48 \mathrm{IU} / \mathrm{L}(<0.15-1.82)$ at week 4 and numerically declined during the treatment period (Figure 2(a)). Mean basal FSH decreased from $4.1 \mathrm{IU} / \mathrm{L}$ at baseline to $0.8 \mathrm{IU} / \mathrm{L}$
(0.15-1.97) by week 4 and was <1.5 IU/L for the duration of treatment (Figure 2(b)). Mean basal estradiol decreased from $57.28 \mathrm{pmol} / \mathrm{L}(15.6 \mathrm{pg} / \mathrm{mL})$ at baseline to the lower limit of detection $(18.36 \mathrm{pmol} / \mathrm{L}(5.0 \mathrm{pg} / \mathrm{mL}))$ by study week 4 . Almost all postbaseline estradiol levels (99.2\%) were below the threshold of detection.

The mean peak LH: peak FSH ratio in females was 2.6 (1.0-6.2) at baseline, decreased to $0.9(0.2-3.0)$ at week 4 , and trended downward during the course of treatment (Figure 3(a)). The mean ratio was $\leq 0.5$ from the second year onward. The mean basal LH: basal FSH ratio numerically decreased as treatment progressed (Figure 3(b)), coordinate with the opposite trends in basal LH and FSH.

Regression or no progression of breast Tanner stage was observed at week 4 in $81.8 \%$ of females. Over 4 years, the percentage of patients with regression or no progression of breast stage from baseline at each visit ranged from $66.7 \%$ to $90.6 \%$. Uterine bleeding or spotting occurred in 15 females (31\%) during the first 4 weeks of treatment (8/15 with prior history of bleeding). Those 15 girls exhibited a higher mean serum basal estradiol at baseline compared with the 33 girls who did not have subsequent bleeding $(83.2 \pm 53.2$ $\mathrm{pmol} / \mathrm{L}(22.7 \pm 14.5 \mathrm{pg} / \mathrm{mL})$ versus $44.1 \pm 58.6 \mathrm{pmol} / \mathrm{L}(12.0$ $\pm 16.0 \mathrm{pg} / \mathrm{mL}), P=.0325)$. They also had higher baseline basal LH levels $(3.46 \pm 2.95 \mathrm{IU} / \mathrm{L}$ versus $1.41 \pm 1.08 \mathrm{IU} / \mathrm{L}, P<$ $.001)$. Uterine bleeding or spotting after week 4 was reported in 7 females, all in the absence of detectable estradiol.

3.3. Treatment Period: Males. In males, mean start age was $7.9 \pm 2.0$ years, mean age at discontinuation was $12.4 \pm 1.2$ years (11.1-14.1), and mean duration was 4.6 years (1.97.9). Mean peak LH decreased from 21.2 IU/L at baseline to $0.7 \mathrm{IU} / \mathrm{L}$ at week 4 . During the treatment period, one male had a peak stimulated $\mathrm{LH}$ value $\geq 1.75 \mathrm{IU} / \mathrm{L}$. Mean peak FSH decreased from $5.6 \mathrm{IU} / \mathrm{L}$ at baseline to $0.5 \mathrm{IU} / \mathrm{L}$ at week 4 . Comparable to the females, mean basal LH was suppressed to $0.5 \mathrm{IU} / \mathrm{L}$ at week 4 and was $\leq 0.4 \mathrm{IU} / \mathrm{L}$ for the duration of treatment. Mean basal FSH in males decreased from $2.4 \mathrm{IU} / \mathrm{L}$ at baseline to $0.5 \mathrm{IU} / \mathrm{L}$ by week 4 and was $\leq 0.8 \mathrm{IU} / \mathrm{L}$ during the treatment period. Mean basal testosterone decreased from $6.93 \mathrm{nmol} / \mathrm{L}(199.8 \mathrm{ng} / \mathrm{dL})$ at baseline to $0.62 \mathrm{nmol} / \mathrm{L}$ $(17.8 \mathrm{ng} / \mathrm{dL})$ at week 4 and never exceeded $0.84 \mathrm{nmol} / \mathrm{L}$ ( $24 \mathrm{ng} / \mathrm{dL})$ during treatment, but 5/6 males had treatment levels above the prepubertal threshold/limit of detection of $0.35 \mathrm{nmol} / \mathrm{L}(10 \mathrm{ng} / \mathrm{dL})$. Testosterone in 3 males was intermittently above $1.04 \mathrm{nmol} / \mathrm{L}(30 \mathrm{ng} / \mathrm{dL})$, with a maximum testosterone of $1.94 \mathrm{nmol} / \mathrm{L}(56 \mathrm{ng} / \mathrm{dL})$. Regression or nonprogression of genital Tanner stage was observed in 5/6 males. Progression from 2 to 3 occurred in the male with the highest testosterone level and a transient peak LH $\geq 1.75 \mathrm{IU} / \mathrm{L}$.

3.4. Dose Modifications and Adverse Events during Treatment. The dose was increased in eight patients. Five were females with stimulated $\mathrm{LH}>1.75 \mathrm{IU} / \mathrm{L}$, including the 2 youngest subjects ( 1 year olds, one with a hamartoma). The dose was also increased in the male patient with elevated testosterone, peak $\mathrm{LH}>1.75 \mathrm{IU} / \mathrm{L}$, and Tanner stage progression. All 6 patients suppressed to peak stimulated $\mathrm{LH} \leq 1.75 \mathrm{IU} / \mathrm{L}$ after 


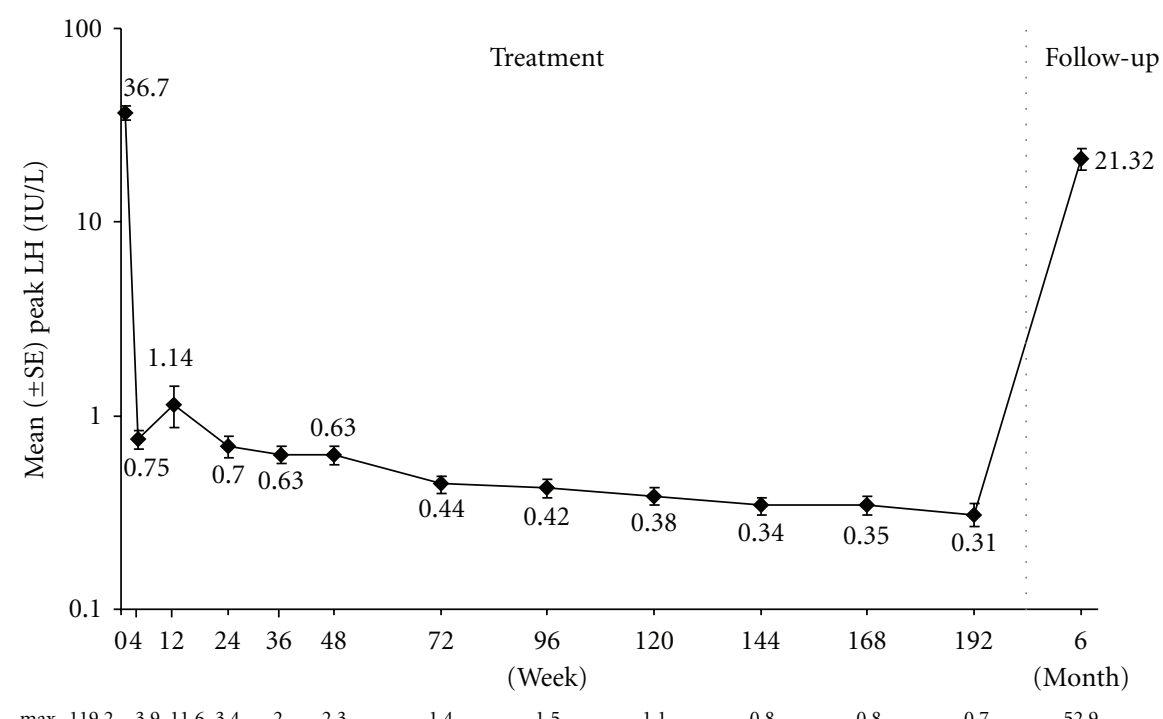

(a)

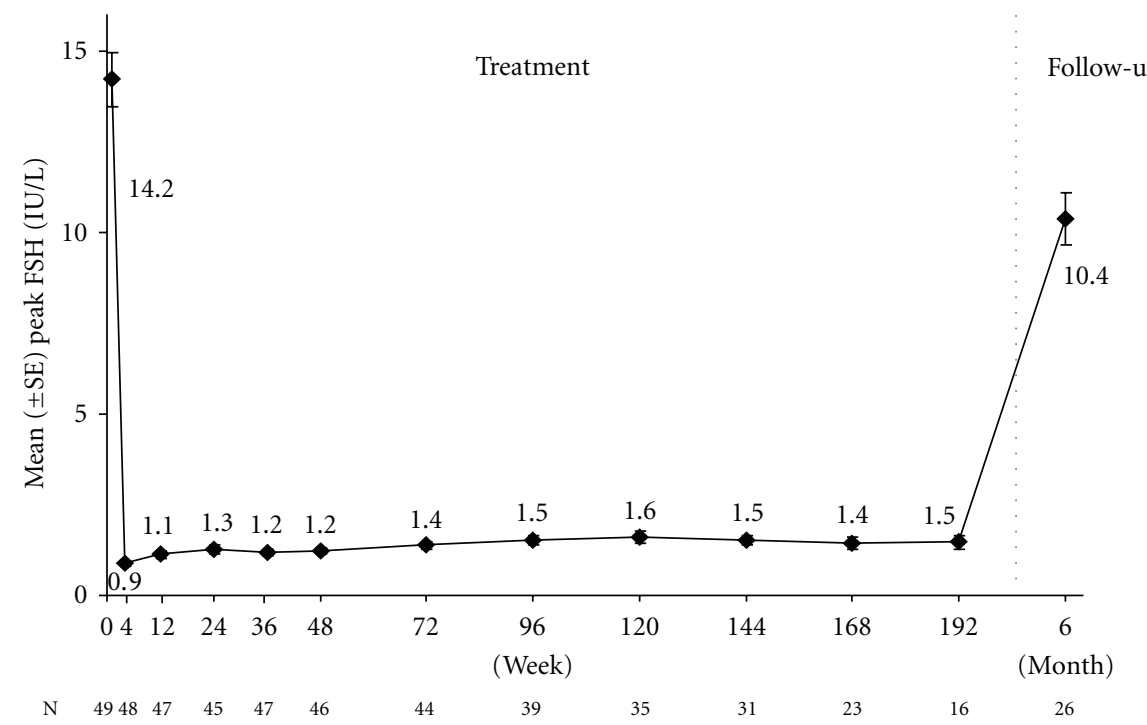

(b)

FIGURE 1: Mean peak stimulated LH (a, log scale) and FSH (b) for females during the treatment and follow-up periods. Mean concentrations for peak LH and FSH at each study visit are displayed adjacent to the respective points. Maximum individual concentrations for peak LH at each study visit are indicated on panel (a). The number of subjects at each study visit is indicated beneath panel (b).

the first year. In 2 additional females, a dose adjustment was made due to weight increase.

Long-term treatment with leuprolide acetate 1-month depot was well tolerated. There were no clinically relevant changes in hematology or chemistry values. Adverse events reported in $\geq 5 \%$ of patients possibly or probably related to study drug are shown in Table 2. Eleven patients had $>1$ adverse event related to injections, including reported pain $(n=8)$, reaction $(n=3)$, inflammation $(n=2)$, and/or edema $(n=1)$. None of the injection-site adverse events were serious or led to premature discontinuation. Two serious events possibly related to study drug occurred, a severe asthma exacerbation and an increase in size of a preexisting optic glioma with deteriorating vision. There was a death during the study considered unrelated by the investigator, a cardiopulmonary arrest following respiratory infection. Nine patients discontinued study drug prematurely for reasons including patient request to leave the study, noncompliance with visit schedule, lost to follow-up, and the death described above. No patients withdrew due to injection reaction or failure to achieve adequate suppression.

3.5. Posttreatment Follow-Up Period. Thirty-five females entered the posttreatment follow-up period. Most (66.7\%) had breast stage advance by the first posttreatment visit. Tanner breast stage 5 was achieved by $78 \%$ of females within the first 3 years of follow-up and in $100 \%$ of female patients within the 5 year follow-up. Mean peak LH and 


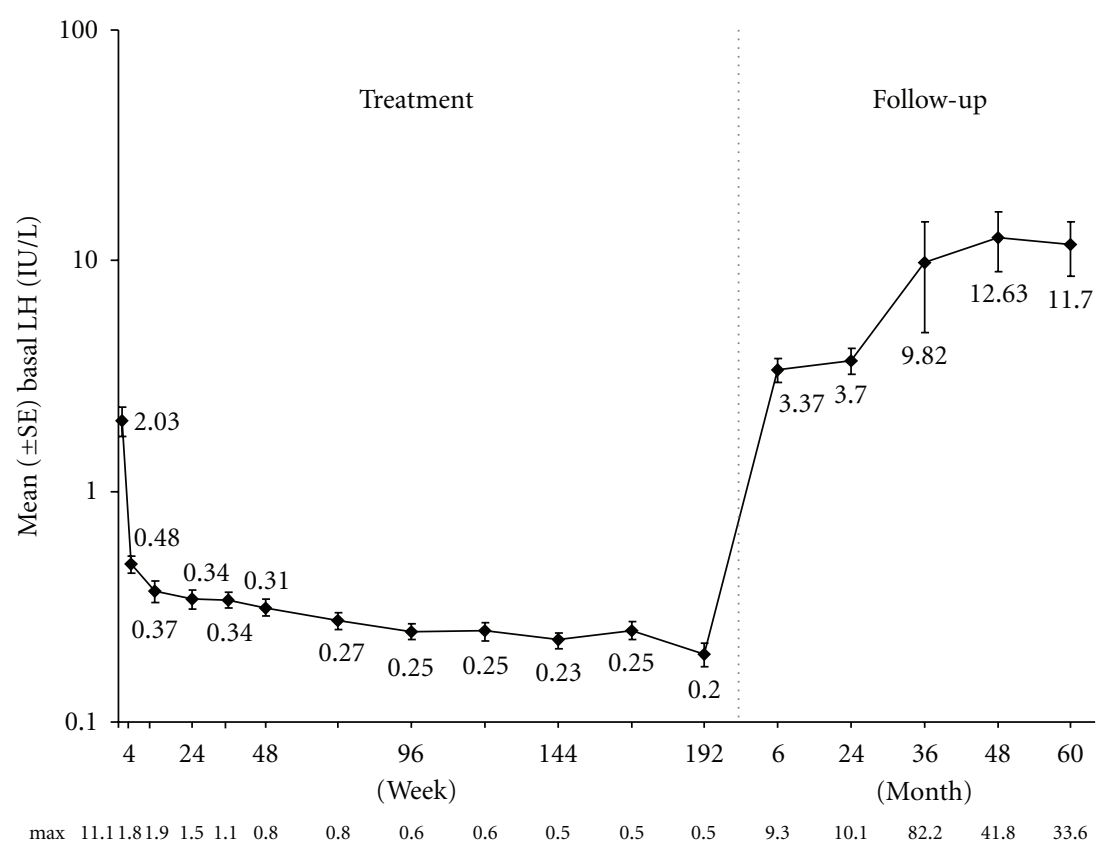

(a)

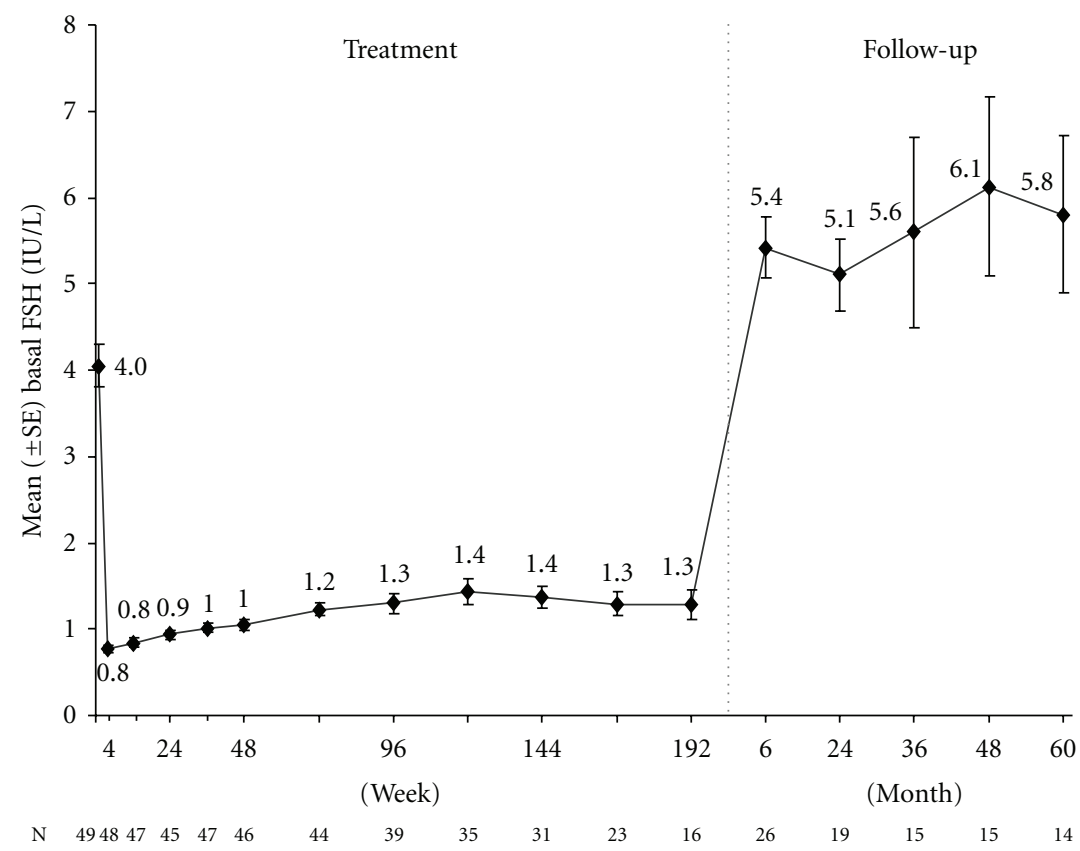

(b)

Figure 2: Mean basal LH (a, log scale) and FSH (b) for females during the treatment and follow-up periods. Mean values for basal LH and FSH are displayed adjacent to the respective points. Maximum individual concentrations for basal LH at each study visit are indicated on panel (a). The number of subjects at each study visit is indicated beneath panel (b).

FSH concentrations in females increased to $21.3 \mathrm{IU} / \mathrm{L}$ ( 0.28 52.9) and 10.4 IU/L (1.2-18.4), respectively, at the 6 month visit (Figure 1). Mean peak LH: peak FSH ratio rose to 1.9 $\pm 0.9 \mathrm{IU} / \mathrm{L}$ at the 6 month visit (Figure 3(a)). All females achieved a pubertal GnRH-stimulated response within 1 year of treatment discontinuation. Mean basal LH increased to $3.4 \mathrm{IU} / \mathrm{L}(<0.15-9.3)$ by 6 months posttreatment and to
11.7 IU/L in the females who still remained in the study at the 5 year follow-up (Figure 2(a)). Mean basal FSH increased to $5.4 \mathrm{IU} / \mathrm{L}(0.95-9.3)$ in females at 6 months and was $5.8 \mathrm{IU} / \mathrm{L}$ at the 5 year follow-up (Figure 2(b)). Mean basal $\mathrm{LH}$ : basal FSH ratio rose to $0.6 \pm 0.3$ by the 6 month visit (Figure 3(b)) and further increased during reestablishment of puberty, reaching $1.8 \pm 1.3$ at the 5 year visit. Mean 


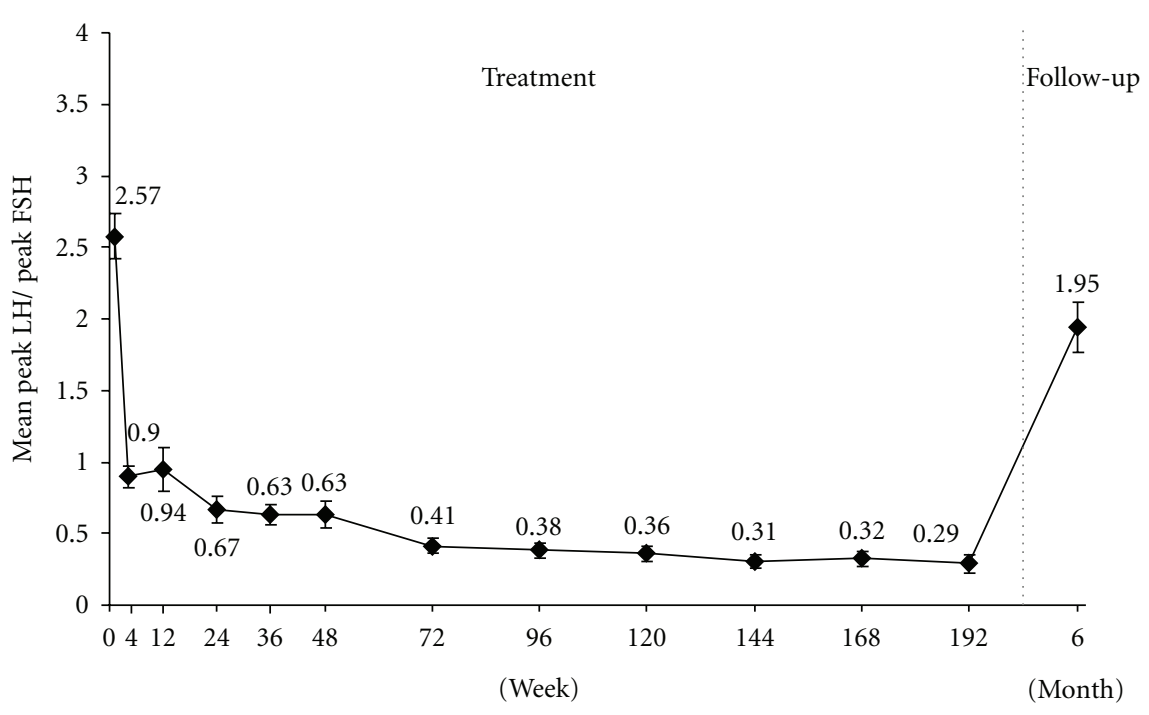

(a)

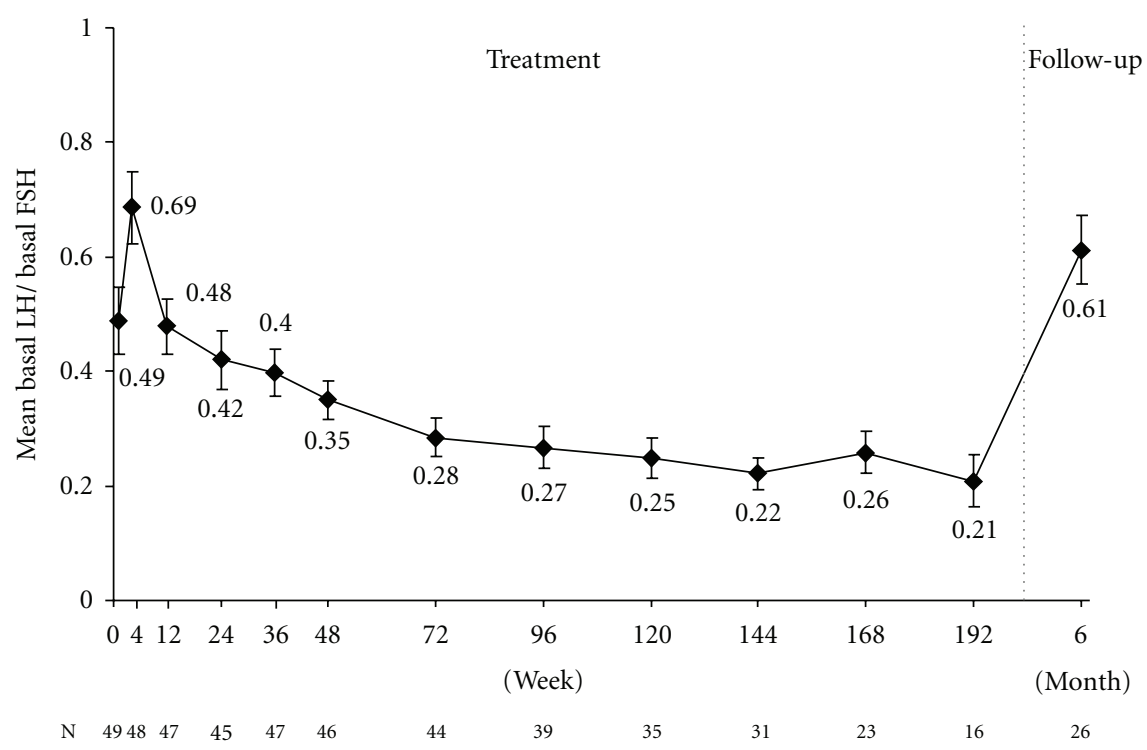

(b)

Figure 3: Mean peak LH: peak FSH ratio (a) and mean basal LH: basal FSH ratio (b) for females during the treatment period and at the 6 month follow-up visit. The mean ratios at each study visit are displayed adjacent to the respective points. The number of subjects at each study visit is indicated beneath panel (b).

estradiol increased to $60.4 \mathrm{pmol} / \mathrm{L}(16.4 \mathrm{pg} / \mathrm{mL})$ by 6 months and to $281.7 \mathrm{pmol} / \mathrm{L}(76.7 \mathrm{pg} / \mathrm{mL})$ by 5 years.

Menses were reported for 27/32 female patients during the follow-up period. The remaining 5 patients were less than 12 years of age when they discontinued from long-term follow-up. Mean time from discontinuation to first menses was $1.5 \pm 0.5$ years $(0.5-2.5$ years $)$, and the mean age was $12.9 \pm 0.9$ years $(11.6-14.9$ years $)$. In those patients who had menses prior to treatment $(n=7)$, the average time to resumption of menses was $1.4 \pm 0.5$ years $(0.5-2.1$ years), and for those patients without menses prior to treatment $(n=19)$, elapsed time was $1.6 \pm 0.5$ years $(0.5-2.5$ years $)$.

Five males entered the follow-up study, 4 of whom showed Tanner genital stage advance by 6 months. Mean peak LH and FSH rose to 16.0 IU/L and 8.7 IU/L, respectively, mean basal LH and FSH were 2.8 IU/L and 4.4 IU/L, respectively, and basal testosterone was $6.7 \mathrm{nmol} / \mathrm{L}(194 \mathrm{ng} / \mathrm{dL})$ at 6 months. All 5 males achieved the defined pubertal response by 1 year posttreatment.

3.6. Adult Follow-Up. Data to assess reproductive function, including menstrual cycles, pregnancy, and reported history of ovarian cysts, were collected in a post-study survey of 20 girls who reached adulthood (ages 18-26). Menstrual cycles were reported to be normal in $80 \%$ of women and use of birth control medication was reported in 7/20 patients. Ovarian volumes were assessed by ultrasound in 11 patients and revealed normal ranges; only small follicular cysts were 
TABLE 2: Adverse events possibly or probably related to study drug in $\geq 5 \%$ of subjects.

\begin{tabular}{lc}
\hline & Number of subjects (\%) \\
COSTART term & $N=55$ \\
\hline Any adverse event & $34(62)$ \\
Emotional lability & $10(18)$ \\
Injection site pain & $8(15)$ \\
Headache & $6(11)$ \\
Acne & $5(9)$ \\
Pain & $4(7)$ \\
Vasodilatation $^{\mathrm{a}}$ & $4(7)$ \\
Growth retarded & b \\
Vaginitis $^{\text {Injection site reaction }}{ }^{\mathrm{c}}$ & $4(7)$ \\
Menstrual disorder $^{\mathrm{d}}$ & $4(7)$ \\
Weight gain & $3(5)$ \\
\hline
\end{tabular}

${ }^{a}$ Vasodilation = flushing and/or hot flashes.

${ }^{\mathrm{b}}$ Growth retarded = slowing of growth.

${ }^{\mathrm{c}}$ Injection site reaction $=$ injection site reaction, injection site hypersensitivity, edema, mass, pain, cyst, atrophy, fibrosis, rash, necrosis, inflammation, abscess, hematoma, granuloma, induration.

$\mathrm{d}_{\text {Menstrual disorder }}=$ menstrual spotting, vaginal bleeding, and cramping.

reported, including in the 2 females with reported polycystic ovarian syndrome. Twelve pregnancies were reported in 7/20 patients, including multiple pregnancies for 4 . There were 6 live births, 5 spontaneous or elective terminations, and 1 ongoing pregnancy; no stillbirths were reported. Four out of 4 women who attempted to become pregnant became pregnant. Two women who reported difficulty conceiving had achieved live births.

\section{Discussion}

Treatment with leuprolide acetate 1-month depot has been routine therapy for CPP for over 15 years. This report from the initial US multicenter trial provides details regarding suppression of gonadotropins and sex steroids during treatment, hormonal and clinical progression during long-term posttreatment follow-up, and review of reproductive health at adulthood.

During the treatment period, on average 4 years, leuprolide acetate depot rapidly controlled clinical signs of puberty and suppressed hormones to prepubertal levels. In females, mean peak LH dropped by over $97 \%$ after the first injection. However, the protocol called for an increase in dose for any peak LH $>1.75 \mathrm{IU} / \mathrm{L}$, a rigorous outcome measure equivalent to prepubertal means $(17,18,21,22)$. This resulted in dose increases in the first year of treatment in 6 subjects, but no stimulated LH levels surpassed this cutoff after the 48 week visit. It is unknown whether that outcome was solely attributable to duration of treatment or partially to increases in dose in some patients. Overall, mean peak $\mathrm{LH}$ in females trended downward during therapy, whereas mean peak FSH trended slightly upward. As a consequence, the peak LH:peak FSH ratio gradually declined during therapy, returning subjects to the gonadotropin pattern seen in normal prepubertal girls.

At baseline, the age, sex ratio, and Tanner stage were typical of patients with CPP. However, the conservative entry threshold of peak $\mathrm{LH} \geq 10 \mathrm{IU} / \mathrm{L}$, plus the BA advance criterion, likely excluded some patients who in current clinical practice might be treated. Thus the cohort might have been more advanced in puberty than in other CPP studies, as the mean peak LH of $36 \mathrm{IU} / \mathrm{L}$ in females and BA advance of approximately 3 years demonstrate. The relatively advanced puberty may explain the high percentage of girls with menses prior to treatment $(25 \%)$, which in turn could be linked to the proportion of girls with bleeding following estrogen withdrawal in the first month (31\%). Girls with bleeding during therapy had higher baseline estradiol and LH levels; however, a surprising number of girls showed continued spotting after hormonal suppression was established.

This study was initiated when GnRH for stimulation testing was still available in the US. The peak LH levels at diagnosis of CPP were observed in almost all subjects within 40 minutes after GnRH injection, and with highly consistent levels among timed samples, supporting the concept that stimulation testing using multiple samples or for extended duration is unnecessary [17-19]. Basal LH has been recommended as a surrogate for peak $\mathrm{LH}$ in diagnosis of CPP [20,21]; in this study basal LH correlated modestly with peak LH at diagnosis, although in some subjects the diagnostic peak LH was not associated with a clearly pubertal basal LH. Thus, basal LH has reasonable sensitivity as a screen and perhaps in most instances is adequate to diagnose CPP [22], while stimulation testing (now using aqueous leuprolide acetate) may sometimes be required and may help differentiate FSH-predominant nonprogressive premature thelarche from LH-predominant CPP.

The DELFIA LH and FSH assays utilized in the study are highly sensitive and widely used double-antibody assays [23]. The rigorous lower LH detection limit of $0.15 \mathrm{IU} / \mathrm{L}$ was not relevant at the relatively high concentrations of basal and peak LH at diagnosis. However, as treatment progressed, increasing percentages of basal and peak LH levels were at or below the threshold of detectability. Accordingly, the mean values for basal and peak LH during therapeutic monitoring are possibly overstated, as many of the true levels were likely less than the threshold $0.15 \mathrm{IU} / \mathrm{L}$ used to calculate the means.

The standard for monitoring the early phase of GnRHa therapy has been the observation of clinical parameters, especially pubertal staging and growth rate, and assessment of peak LH. In the US, the latter now requires blood obtained after aqueous leuprolide injection or following leuprolide acetate depot itself [17]. For convenience, some practitioners monitor therapy using unstimulated basal LH levels. Our data demonstrate that this practice should be used cautiously, particularly in the first year of therapy, when basal LH levels are routinely elevated above prepubertal norms $[20,21,24]$. Like peak LH, basal LH showed a downward trend during treatment, with the mean falling to approximately $0.3 \mathrm{IU} / \mathrm{L}$ by 24 weeks. However, many subjects with suppressed peak LH exhibited basal LH concentrations in the $0.5-1 \mathrm{IU} / \mathrm{L}$ pubertal range. 
Despite the high peak LH threshold required for study entry, $33 \%$ of girls did not have detectable estradiol at baseline, demonstrating its limited utility for diagnosis of CPP. This is plausibly attributable to assay threshold or to physiologic variability. The study RIA measured to $18.36 \mathrm{pmol} / \mathrm{L}$ $(5 \mathrm{pg} / \mathrm{mL})$, whereas estradiol can now be measured by MS/MS to approximately $7.34 \mathrm{pmol} / \mathrm{L}(2 \mathrm{pg} / \mathrm{mL})$. Even that threshold is well above normal prepubertal levels [25], and as a consequence estradiol was not detectable during the treatment phase of our study. Estradiol measurement during therapy can at best confirm complete treatment failure.

The testosterone RIA in our study measured to $0.347 \mathrm{nmol} / \mathrm{L}(10 \mathrm{ng} / \mathrm{dL})$, close to the prepubertal threshold reported for MS/MS. For reasons of assay sensitivity, testosterone can generally be considered a better screen of CPP (in combination with confirmatory LH) in males compared with estradiol in females. Testosterone levels fell steeply after the first injection, but 5/6 males intermittently exceeded the prepubertal norm, despite suppressed LH levels. This presents a clinical management dilemma whether to accept marginally detectable testosterone levels, which may not respond to more aggressive dosing. Alternative explanations for incompletely suppressed testosterone include assay inaccuracy in the lower range, testosterone of adrenal origin, or persistent gonadal testosterone secretion despite apparent gonadotropin suppression.

After discontinuation of treatment, subjects were followed for an average of 3.5 years. All subjects had resumption of the pubertal hypothalamic-pituitary-gonadal axis within 12 months, and most by 6 months, with LH, FSH, and estradiol or testosterone all returning to pubertal levels. The resumption of puberty was also evidenced by progression of Tanner stages in both females and males. In females, the mean time to onset of menses was approximately 1.5 years, consistent with previous studies in females treated with GnRHa, in which the interval ranged from 2 to 61 months, with an average of approximately 16 months $[6,13,26-28]$. Furthermore, the mean age at the onset of menarche or remenarche in our study was 12.9 years, which is consistent with the average age of menarche of 12.53 years in the US [29]. Reassuringly, all females over 12 years old reported menses by the end of the follow-up phase.

At callback of adult subjects we did not find impairment in reproductive function, consistent with previous studies $[6,8,13,30]$. A study by Heger et al. reported 12 pregnancies in 34 women who wished to have children [6]. In the current study, 7 women reported a total of 12 pregnancies. Although definitive conclusion regarding long-term reproductive function is weakened by the limited number of patients that could be located at callback more than a decade after the end of treatment, the universal normalcy of hormone levels and menses during the follow-up period and lack of reported problems in adulthood are all reassuring.

In summary, treatment with leuprolide acetate 1-month depot effectively suppressed the GnRH axis for the duration of therapy in all subjects. It was well tolerated, with no clinically relevant injection-site reactions in any of the 55 subjects. Most subjects exhibited recovery to pubertal hormone levels 6 months after discontinuation of treatment, and mean onset of menses was 1.5 years after discontinuation. Long-term follow-up and adult callback revealed that the interruption of the GnRH axis in children with CPP did not impair reproductive function in adulthood.

\section{Disclosure}

E. Kirk Neely has received grant/research support from and has been a consultant and scientific advisory board member for Abbott. Peter A. Lee has been a consultant for Abbott and Novo Nordisk with grants from Abbott, Eli Lilly, Novo Nordisk, Pfizer, and Ipsen. Clifford A. Bloch has been a consultant to Abbott. Lois Larsen, Di Yang, Cynthia Mattia-Goldberg, and Kristof Chwalisz are all employees of Abbott and Lois Larsen, Cynthia Mattia-Goldberg, and Kristof Chwalisz all own Abbott stock.

\section{Acknowledgments}

Financial support for this study was provided by Abbott Laboratories, formerly TAP. Medical writing support was provided by A. J. Fein, $\mathrm{PhD}$ on behalf of Abbott. The authors would like to thank the following investigators for their participation in the study: B. B. Bercu, MD; S. A Chalew, MD; F. A. Conte, MD; R. Hintz, MD; J. S. Fuqua, MD; M. S. Kappy, MD; G. J. Klingensmith, MD; and E. O. Reiter, MD.

\section{References}

[1] J.-C. Carel, E. A. Eugster, A. Rogol et al., "Consensus statement on the use of gonadotropin-releasing hormone analogs in children," Pediatrics, vol. 123, no. 4, pp. e752-e762, 2009.

[2] D. Mul, I. A. Hughes, and E. G. A. H. Van Mil, "The use of GnRH agonists in precocious puberty," European Journal of Endocrinology, Supplement, vol. 159, supplement 1, pp. S3-S8, 2008.

[3] E. Cacciari, A. Cassio, A. Balsamo et al., "Long-term followup and final height in girls with central precocious puberty treated with luteinizing hormone-releasing hormone analogue nasal spray," Archives of Pediatrics and Adolescent Medicine, vol. 148, no. 11, pp. 1194-1199, 1994.

[4] J.-C. Carel, M. Roger, S. Ispas et al., "Final height after long-term treatment with triptorelin slow release for central precocious puberty: importance of statural growth after interruption of treatment," Journal of Clinical Endocrinology and Metabolism, vol. 84, no. 6, pp. 1973-1978, 1999.

[5] R. D. Clemons, M. S. Kappy, T. E. Stuart, A. H. Perelman, and F. T. Hoekstra, "Long-term effectiveness of depot gonadotropin-releasing hormone analogue in the treatment of children with central precocious puberty," American Journal of Diseases of Children, vol. 147, no. 6, pp. 653-657, 1993.

[6] S. Heger, M. Müller, M. Ranke et al., "Long-term GnRH agonist treatment for female central precocious puberty does not impair reproductive function," Molecular and Cellular Endocrinology, vol. 254-255, pp. 217-220, 2006.

[7] S. Heger, C. J. Partsch, and W. G. Sippell, "Long-term outcome after depot gonadotropin-releasing hormone agonist treatment of central precocious puberty: final height, body proportions, body composition, bone mineral density, and reproductive function," Journal of Clinical Endocrinology and Metabolism, vol. 84, no. 12, pp. 4583-4590, 1999. 
[8] M. A. Magiakou, D. Manousaki, M. Papadaki et al., "The efficacy and safety of gonadotropin-releasing hormone analog treatment in childhood and adolescence: a single center, longterm follow-up study," Journal of Clinical Endocrinology and Metabolism, vol. 95, no. 1, pp. 109-117, 2010.

[9] E. K. Neely, R. L. Hintz, B. Parker et al., "Two-year results of treatment with depot leuprolide acetate for central precocious puberty," Journal of Pediatrics, vol. 121, no. 4, pp. 634-640, 1992.

[10] W. Oostdijk, S. L. Drop, R. J. Odink, R. Hümmelink, C. J. Partsch, and W. G. Sippell, "Long-term results with a slowrelease gonadotrophin-releasing hormone agonist in central precocious puberty. Dutch-German Precocious Puberty Study Group," Acta Paediatrica Scandinavica, Supplement, vol. 372, pp. 39-46, 1991.

[11] W. Oostdijk, B. Rikken, S. Schreuder et al., "Final height in central precocious puberty after long term treatment with a slow release GnRH agonist," Archives of Disease in Childhood, vol. 75, no. 4, pp. 292-297, 1996.

[12] C.-J. Partsch, S. Heger, and W. G. Sippell, "Treatment of central precocious puberty: lessons from a 15 years prospective trial," Journal of Pediatric Endocrinology and Metabolism, vol. 13, supplement 1, pp. 747-758, 2000.

[13] A. M. Pasquino, I. Pucarelli, F. Accardo, V. Demiraj, M. Segni, and R. Di Nardo, "Long-term observation of 87 girls with idiopathic central precocious puberty treated with gonadotropinreleasing hormone analogs: impact on adult height, body mass index, bone mineral content, and reproductive function," Journal of Clinical Endocrinology and Metabolism, vol. 93, no. 1, pp. 190-195, 2008.

[14] T. Tanaka, H. Niimi, N. Matsuo et al., "Results of long-term follow-up after treatment of central precocious puberty with leuprorelin acetate: evaluation of effectiveness of treatment and recovery of gonadal function. The TAP-144-SR Japanese study group on central precocious puberty," Journal of Clinical Endocrinology and Metabolism, vol. 90, no. 3, pp. 1371-1376, 2005.

[15] P. A. Lee, E. K. Neely, J. Fuqua et al., "Efficacy of leuprolide acetate 1-month depot for central precocious puberty (CPP): growth outcomes during a prospective, longitudinal study," International Journal of Pediatric Endocrinology. In press.

[16] A. F. Roche, W. C. Chumlea, and D. Thissen, Assessing the Skeletal Maturity of the Hand Wrist: FELS Method, Charles C. Thomas, Springfield, III, USA, 1988.

[17] S. Bhatia, E. K. Neely, and D. M. Wilson, "Serum luteinizing hormone rises within minutes after depot leuprolide injection: implications for monitoring therapy," Pediatrics, vol. 109, no. 2, p. E30, 2002.

[18] V. N. Brito, M. C. Batista, M. F. Borges et al., "Diagnostic value of fluorometric assays in the evaluation of precocious puberty," Journal of Clinical Endocrinology and Metabolism, vol. 84, no. 10, pp. 3539-3544, 1999.

[19] P. A. Lee, "Laboratory monitoring of children with precocious puberty," Archives of Pediatrics and Adolescent Medicine, vol. 148, no. 4, pp. 369-376, 1994.

[20] C. P. Houk, A. R. Kunselman, and P. A. Lee, "The diagnostic value of a brief $\mathrm{GnRH}$ analogue stimulation test in girls with central precocious puberty: a single 30-minute poststimulation LH sample is adequate," Journal of Pediatric Endocrinology and Metabolism, vol. 21, no. 12, pp. 1113-1118, 2008.

[21] E. K. Neely, D. M. Wilson, P. A. Lee, M. Stene, and R. L. Hintz, "Spontaneous serum gonadotropin concentrations in the evaluation of precocious puberty," Journal of Pediatrics, vol. 127, no. 1, pp. 47-52, 1995.

[22] C. P. Houk, A. R. Kunselman, and P. A. Lee, "Adequacy of a single unstimulated luteinizing hormone level to diagnose central precocious puberty in girls," Pediatrics, vol. 123, no. 6, pp. e1059-e1063, 2009.

[23] V. N. Brito, A. C. Latronico, P. Cukier et al., "Factors determining normal adult height in girls with gonadotropin- dependent precocious puberty treated with depot gonadotropin-releasing hormone analogs," Journal of Clinical Endocrinology and Metabolism, vol. 93, no. 7, pp. 2662-2669, 2008.

[24] E. A. M. R. De Resende, B. H. J. Lara, J. D. Reis, B. P. Ferreira, G. A. Pereira, and M. F. Borges, "Assessment of basal and gonadotropin-releasing hormone-stimulated gonadotropins by immunochemiluminometric and immunofluorometric assays in normal children," Journal of Clinical Endocrinology and Metabolism, vol. 92, no. 4, pp. 1424-1429, 2007.

[25] K. O. Klein, V. Mericq, J. M. Brown-Dawson, K. A. Larmore, P. Cabezas, and A. Cortinez, "Estrogen levels in girls with premature thelarche compared with normal prepubertal girls as determined by an ultrasensitive recombinant cell bioassay," Journal of Pediatrics, vol. 134, no. 2, pp. 190-192, 1999.

[26] T. Arrigo, F. De Luca, F. Antoniazzi et al., "Menstrual cycle pattern during the first gynaecological years in girls with precocious puberty following gonadotropin-releasing hormone analogue treatment," European Journal of Pediatrics, vol. 166, no. 1, pp. 73-74, 2007.

[27] A. Cassio, M. O. Bal, L. F. Orsini et al., "Reproductive outcome in patients treated and not treated for idiopathic early puberty: long-term results of a randomized trial in adults," Journal of Pediatrics, vol. 149, no. 4, pp. 532-536, 2006.

[28] P. P. Feuillan, J. V. Jones, K. Barnes, K. Oerter-Klein, and G. B. Cutler Jr., "Reproductive axis after discontinuation of gonadotropin-releasing hormone analog treatment of girls with precocious puberty: long term follow- up comparing girls with hypothalamic hamartoma to those with idiopathic precocious puberty," Journal of Clinical Endocrinology and Metabolism, vol. 84, no. 1, pp. 44-49, 1999.

[29] S. E. Anderson and A. Must, "Interpreting the continued decline in the average age at menarche: results from two nationally representative surveys of U.S. girls studied 10 years apart," Journal of Pediatrics, vol. 147, no. 6, pp. 753-760, 2005.

[30] N. Jay, M. J. Mansfield, R. M. Blizzard et al., "Ovulation and menstrual function of adolescent girls with central precocious puberty after therapy with gonadotropin-releasing hormone agonists," Journal of Clinical Endocrinology and Metabolism, vol. 75, no. 3, pp. 890-894, 1992. 